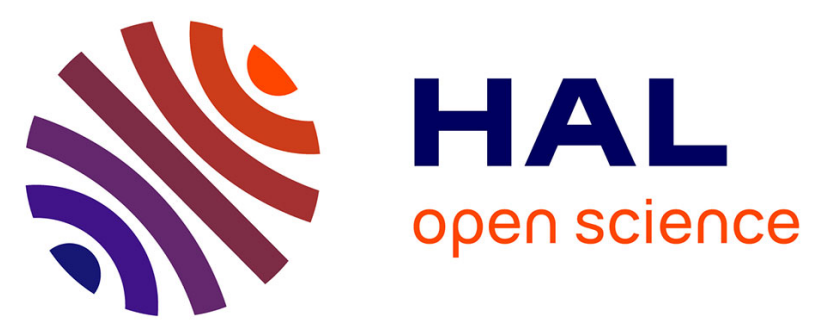

\title{
Structural basis for mannose recognition by alectin from opportunistic bacteria Burkholderia cenocepacia
}

Emilie Lameignere, Lenka Malinovska, Margita Slavikova, Éric Duchaud, Edward P Mitchell, Annabelle Varrot, Ondrej Sedo, Anne Imberty, Michaela

Wimmerova

\section{To cite this version:}

Emilie Lameignere, Lenka Malinovska, Margita Slavikova, Éric Duchaud, Edward P Mitchell, et al.. Structural basis for mannose recognition by alectin from opportunistic bacteria Burkholderia cenocepacia. Biochemical Journal, 2008, 411 (2), pp.307-318. 10.1042/bj20071276 . hal-00479454

\section{HAL Id: hal-00479454 https://hal.science/hal-00479454}

Submitted on 30 Apr 2010

HAL is a multi-disciplinary open access archive for the deposit and dissemination of scientific research documents, whether they are published or not. The documents may come from teaching and research institutions in France or abroad, or from public or private research centers.
L'archive ouverte pluridisciplinaire HAL, est destinée au dépôt et à la diffusion de documents scientifiques de niveau recherche, publiés ou non, émanant des établissements d'enseignement et de recherche français ou étrangers, des laboratoires publics ou privés. 


\section{Structural basis for mannose recognition by a lectin from opportunistic bacteria Burkholderia cenocepacia}

Emilie Lameignere* ${ }^{1}$, Lenka Malinovská $\dagger^{1}$, Margita Sláviková†, Eric Duchaudł, Edward P. Mitchell§, Annabelle Varrot*, Ondrej Šedo\|, Anne Imberty*2 and Michaela Wimmerová $\dagger^{2}$

*CERMAV-CNRS (affiliated with Université Joseph Fourier and belonging to ICMG), BP 53, F-38041, Grenoble, Cedex 09, France

$\uparrow$ National Centre for Biomolecular Research and Institute of Biochemistry, Masaryk University, Kotlarska 2, 61137 Brno, Czech Republic

† INRA, Unité Virologie et Immunologie Moléculaires UR892, Jouy-en-Josas, France

$\S$ E.S.R.F. Experiments Division, BP 220, F-38043, Grenoble Cedex, France

|| Department of Functional Genomics and Proteomics, Institute of Experimental Biology, Masaryk University, Kotlarska 2, 61137 Brno, Czech Republic

${ }^{1}$ These authors have contributed equally to the work

${ }^{2}$ Correspondence to:

Dr. Michaela Wimmerová, National Centre for Biomolecular Research and Department of

Biochemistry,Masaryk University, Kotlarska 2, 61137 Brno, Czech Republic, Tel: 420-54949 8166; Fax: : 420-54949 2556; Email: michaw@chemi.muni.cz

Dr. Anne Imberty, CERMAV-CNRS, BP 53, F-38041, Grenoble, Cedex 09, France; Fax: 334-76547203 Email: anne.imberty@cermav.cnrs.fr

Short title: B. cenocepacia lectin BclA

Keywords : bacterial lectin, Burkholderia cenocepacia, Pseudomonas aeruginosa, Burkholderia cepacia complex 
Chronic colonization of the lungs by opportunist bacteria such as Pseudomonas aeruginosa and members of the Burkholderia cepacia complex (Bcc) is the major cause of morbidity and mortality among cystic fibrosis (CF) patients. PA-IIL (lecB gene), a soluble lectin from $P$. aeruginosa, has been the subject of much interest because of its very strong affinity for fucose. Orthologs have been identified in the opportunist bacteria Ralstonia solanacearum, Chromobacterium violaceum and Burkholderia of Bcc. The genome of the J2315 strain of B. cenocepacia, responsible for epidemia in CF centers, contains three genes that code for proteins with PA-IIL domains. The shortest gene was cloned in Escherichia coli and pure recombinant protein, BclA, obtained. The presence of native BclA in B. cenocepacia extracts was checked by proteomics approach. The specificity of recombinant BclA was characterized using surface plasmon resonance showing a preference for mannosides and supported with glycan array experiments demonstrating a strict specificity for oligomannose-type N-glycan structures. The interaction thermodynamics of BclA with $\alpha$-methyl-mannoside ( $\alpha$ MeMan) demonstrates a dissociation constant $(\mathrm{Kd})$ of $2.75 \times 10^{-6} \mathrm{M}$. The X-ray crystal structure of the complex with $\alpha$ MeMan was determined at $1.7 \AA$ resolution. The lectin forms homodimers with one binding site per monomer, acting cooperatively with the second dimer site. Each monomer contains two calcium ions and one sugar ligand. Despite strong sequence similarity, the differences between BclA and PA-IIL in their specificity, binding site, and oligomerisation mode indicate that the proteins should have different roles in the bacteria. 


\section{Introduction}

The Burkholderia cepacia complex (Bcc) is a collection of genetically distinct but phenotypically similar bacteria that are divided into at least nine species [1]. They colonize plant-rhizosphere systems, and water and human environments and their abilities to degrade organic compounds and to produce antimicrobial compounds give them environmental and biotechnological potential [2]. However, the Bcc bacteria are also opportunistic pathogens. Amongst them B. cenocepacia and B. multivorans cause variable lung infections in cystic fibrosis patients, the most dangerous being "cepacia syndrome", which is characterized by a rapid decline in lung function [3-5]. Some strains, with resistance to antibiotics, are also responsible for nosocomial infections.

Bacteria of the B. cepacia complex share many characteristics with Pseudomonas aeruginosa. Both are opportunistic bacteria that are found in various environments including soil, water and vegetation. They can both form biofilms and the occurrence of mixed biofilms has been demonstrated with the use of common signal molecules in the quorum-sensing system [6]. Moreover, a frequent exchange of genetic material has been confirmed between the two organisms [7].

Amongst the virulence factors deployed by $P$. aeruginosa in the infection progress, soluble lectins PA-IL, coded by the lecA gene, and PA-IIL, coded by the lecB gene, have high affinity for galactose and fucose, respectively [8,9]. Their ability to bind to the carbohydrate moiety of mucus or glycoconjugates at epithelial cell surfaces make them good candidates for host recognition and cell surface adhesion. PA-IIL has also been proposed to play a role in biofilm formation [10]. Although orthologs of the lecA gene have not been identified in other pathogenic bacteria at the present time, lecB-like sequences are present in the genomes of Ralstonia solanacearum and Chromobacterium violaceum [11, 12], two opportunistic pathogens that can cause rapid infections and septicemia in immunocompromised humans. Sequence and structural comparisons have shown that the three lectins PA-IIL, RS-IIL and CV-IIL share the same tetrameric arrangement with the unique characteristic of the presence of two calcium ions in the monosaccharide binding site [13-15]. These lectins have unusually high affinity for their monosaccharide ligands (in the micromolar range) and they can bind both L-fucose and D-mannose with their preference depending on a particular stretch of three amino acids in the binding site [9]. 
Since bacteria of the Bcc complex are closely related in behavior and taxonomy to $P$. aeruginosa, it is perhaps not surprising to locate lecB-like genes in the recently sequenced genome of some strains, particularly of B. cenocepacia. Indeed, several genes coding for lectins or lectin domains with similarity to PA-IIL have been identified in each strain. In most cases, an uncharacterised N-terminal domain is attached to the lectin. However, we demonstrate in the present paper that the resulting Burkholderia lectins are rather different to PA-IIL and the other members of this family. We describe here the cloning, production, specificity and structure of $\mathrm{BclA}$, the product of the smallest lecB-like gene from $B$. cenocepacia J2315 which is the ET12 lineage epidemic strain that caused significant mortality amongst CF patients in the UK [16].

\section{Experimental}

Partial purification of native BclA and mass spectrometry characterization

Burkholderia cenocepacia, strain J2315, CCM 4899 = LMG 16656 obtained from the Czech Collection of Microorganisms at Brno, was grown with shaking at $37{ }^{\circ} \mathrm{C}$ in Luria-Bertani (LB) medium overnight. Batches of LB medium (250 $\mathrm{ml}$ in 1-liter Erlenmeyer flasks) were inoculated with $2.5 \mathrm{ml}$ of the overnight culture and D-mannose was added to a final concentration of $50 \mathrm{mM}$. Cells were incubated at $30{ }^{\circ} \mathrm{C}$ with shaking for 4 days. Afterwards, cells were removed by centrifugation and resuspended in $10 \mathrm{ml}$ of $20 \mathrm{mM}$ Tris/HCl buffer, pH 7.5 and disintegrated by sonication. The cytosolic extract was separated by centrifugation, filtered through a $0.22 \mu \mathrm{m}$ sterile filter and applied to a D-mannose-agarose HR5/10 column equilibrated in $20 \mathrm{mM}$ Tris/ $\mathrm{HCl} \mathrm{pH} 7.5,100 \mathrm{mM} \mathrm{NaCl}, 100 \mu \mathrm{M} \mathrm{CaCl}_{2}$. Bound proteins were eluted by $0.1 \%$ SDS, dialyzed overnight against distilled water and lyophilized. Freeze-dried proteins were separated by SDS-polyacrylamide gel electrophoresis (14\% gel) and stained with Coomasie blue R250. A band corresponding to the expected molecular mass of the BclA lectin was excised from the gel and analyzed by mass spectrometry. After destaining, the protein was incubated with trypsin (sequencing grade, Promega) at $37{ }^{\circ} \mathrm{C}$ for $16 \mathrm{~h}$. Digested peptides were extracted from gels using $50 \%$ ACN solution with $5 \%$ formic acid. Protein digests were analyzed by MALDI-MS and subsequently using LC-MS/MS.

MALDI-MS analyses were performed on a Bruker Reflex IV (Bruker Daltonik, Bremen, Germany) operated in reflector mode with detection of positively charged ions using $\alpha$-cyano- 
hydroxycinamnic acid as matrix. LC-MS/MS experiments used an HPLC system consisting of a gradient pump (Ultimate), autosampler (Famos) and column switching device (Switchos; LC Packings, Amsterdam, The Netherlands) coupled with an Esquire 2000 ion-trap mass spectrometer (Bruker Daltonik). Tryptic digests were concentrated and desalted using a PepMap C18 trapping column (300 $\mu \mathrm{m}$ x $5 \mathrm{~mm}$, LC Packings) with a typical sample volume of $10 \mu \mathrm{l}$. After washing with $0.1 \%$ formic acid, the peptides were eluted from the trapping column using an acetonitrile/water gradient $(4 \mu \mathrm{l} / \mathrm{min})$ onto a fused-silica capillary column (320 $\mu \mathrm{m}$ x $180 \mathrm{~mm}$, Jupiter Proteo, 4- $\mu \mathrm{m}$, Phenomenex, Torrance, CA), for peptide separation.

The MASCOT 2.0 (MatrixScience, London, UK) search engine was used for processing the MS and MS/MS data. Sequence searches were done against the NCBI protein database and against local database containing corresponding protein sequences.

\section{Gene cloning}

The oligonucleotide primers were as follows: 5'- GGA GAA ACA TAT GGC TGA TTC TCA AAC GTC-3' (30-mer) and 5'- GTA AGC TTA GCC GAT CGG CCA CTG-3' (24mer). The former is designed for the introduction of NdeI and the latter for HindIII restriction sites (underlined sequences), respectively. PCR was performed using Pfu polymerase (Promega) and genomic DNA from Burkholderia cenocepacia strain J2315 as a template. After digestion with NdeI and HindIII, the amplified fragment was introduced into the multiple cloning site of pRSET vector (Invitrogen) resulting in plasmid pRSETbcla.

\section{Lectin expression, purification and characterization}

E. coli BL21 (DE3) cells containing the plasmid pRSETbcla were cultured in Luria broth medium at $37{ }^{\circ} \mathrm{C}$. When the culture reached an optical density of $0.5-0.6$ at $600 \mathrm{~nm}$, isopropyl- $\beta$-D-thiogalactopyranoside (IPTG) was added to a final concentration of $0.5 \mathrm{mM}$. Cells were harvested after $3 \mathrm{~h}$ incubation at $30{ }^{\circ} \mathrm{C}$, washed and resuspended in equilibrating buffer (20 mM Tris/HCl, $100 \mathrm{mM} \mathrm{NaCl}, 100 \mu \mathrm{M} \mathrm{CaCl}_{2}, \mathrm{pH}$ 7.5). The cells were broken by cell disruption (Constant Cell Disruption System, UK). After centrifugation at $50000 \mathrm{~g}$ for 30 min, $4{ }^{\circ} \mathrm{C}$ and filtration, the supernatant was further purified on a D-mannose-agarose column (Sigma-Aldrich, USA). The BclA lectin was allowed to bind to the immobilised mannose in equilibrating buffer. After washing with buffer $\left(20 \mathrm{mM}\right.$ Tris/ $\mathrm{HCl}, 1 \mathrm{M} \mathrm{NaCl}, 100 \mu \mathrm{M} \mathrm{CaCl}_{2}$, pH 7.5), it was eluted using $20 \mathrm{mM}$ Tris/ $\mathrm{HCl}, 100 \mathrm{mM} \mathrm{NaCl}, 1 \mathrm{mM}$ EDTA, $\mathrm{pH}$ 7.5. The 
purified protein was extensively dialyzed against $5 \mathrm{mM} \mathrm{CaCl} 2$ for two days and against distilled water for a further four days, lyophilized and stored at $-20{ }^{\circ} \mathrm{C}$.

A Superose 12 column (GE Healthcare), equilibrated with $20 \mathrm{mM}$ Tris, $0.3 \mathrm{mM} \mathrm{NaCl}$, pH 7.5 and run at $0.75 \mathrm{ml} / \mathrm{min}$, was used to estimate the molecular mass and oligomeric state of the purified BclA protein. A calibration curve for molecular size estimation was generated by individually loading cytochrome c, myoglobin, ovalbumine and bovine serum albumin.

Further characterization of the BclA lectin was made using dynamic light scattering (DLS) and differential scanning calorimetry (DSC). DSC experiments were performed on a VP-DSC differential scanning micro-calorimeter (Microcal Northampton, MA) at a BclA concentration of $1.1 \mathrm{mM}$ and scan rate of $1.0 \mathrm{~K} / \mathrm{min}$ in $20 \mathrm{mM}$ Tris/ $\mathrm{HCl}, 100 \mathrm{mM} \mathrm{NaCl}, 100 \mu \mathrm{M} \mathrm{CaCl}_{2}, \mathrm{pH}$ 7.5. A background scan collected with buffer in both cells was subtracted from each scan. The DSC data were fitted to a non-two-state unfolding model, which allows estimation of the calorimetric heat change $(\Delta \mathrm{H})$ and the van't Hoff heat change $(\Delta \mathrm{Hv})$ of the thermal unfolding transition. DLS measurements were carried out with a Zetasizer Nano-ZS machine (Malvern instruments Ltd, UK) using DTS software for data acquisition and analysis. Five different concentrations of BclA ranging from 0.4 to $2 \mathrm{mg} / \mathrm{ml}$ in $20 \mathrm{mM}$ Tris $/ \mathrm{HCl}, 100 \mathrm{mM} \mathrm{NaCl}, 100$ $\mu \mathrm{M} \mathrm{CaCl}_{2}, \mathrm{pH} 7.5$ were prepared and size distribution of the particles by intensity and volume were measured.

\section{Surface Plasmon Resonance}

All surface plasmon resonance (SPR) experiments were performed with a Biacore 3000 (Biacore AB, Uppsala, Sweden) at $25^{\circ} \mathrm{C}$ using HBS buffer (10 mM Hepes, $150 \mathrm{mM} \mathrm{NaCl}$, $\mathrm{pH}$ 7.4) and a flow rate of $5 \mu \mathrm{l} / \mathrm{min}$. Two experimental arrangements were used to evaluate the sugar preference of the lectin.

In the first experimental setup, measurements were carried out simultaneously on three measuring channels using different immobilized sugars: D-galactose, D-mannose and L-fucose. Biotinylated polyacrylamide (Biot-PAA) probes bearing sugar moieties (Lectinity corp.) were trapped on a CM5 sensor chip on that was coated with streptavidine using the standard procedure. Each Biot-PAA-monosaccharide (50 $\mu 1$ at concentration $200 \mu \mathrm{g} / \mathrm{ml})$ was injected to the selected channel. Direct binding curves of the lectin to immobilized sugars were measured over a concentration range of 0.06 to $1 \mathrm{mg} / \mathrm{ml}$. For the inhibition studies, BclA was diluted in running buffer to $200 \mu \mathrm{g} / \mathrm{ml}$ and mixed with 10 times concentrated carbohydrate competitor in a 9:1 ratio. This mixture (20 $\mu 1)$ was injected to the CM5 chip at a 
flow rate of $5 \mu \mathrm{l} / \mathrm{min}$. The CM5 chip was regenerated using $100 \mathrm{mM}$ EDTA. Binding was measured as resonance units in time (RU/s) and data were evaluated using the BIAevaluation Software, version 4.1. As BclA does not bind to D-galactose, the corresponding channel was used as a blank. Data were fitted using a kinetic model for 1:1 binding. For the IC50 evaluation, resonance units corresponding to steady-state equillibrium (Req) calculated from fitted curves were taken as the amount of Bcla bound to the sugar surface in the presence of competing monosaccharide.

In the second experimental setup, direct measurements were performed with BclA immobilised on the carboxymethyldextran surface of the CM5 chip. Similarly to the streptavidine immobilisation, the chip was activated with EDC/NHS solution and BclA in 10 $\mathrm{mM}$ acetate buffer, $\mathrm{pH} 4.5$ was injected to the flow channel. Finally, the sensor surface was blocked by $1 \mathrm{M}$ ethanolamine. The blank channel was treated identically except for the lectin injection.

Carbohydrate solutions ( $20 \mu 1$ with concentrations between $0.97 \mu \mathrm{M}$ and $500 \mu \mathrm{M})$ in running buffer were injected into the flow cells using the kinject mode. As the association and dissociation kinetics of monosaccharides was fast, further regeneration of the chip surface was not necessary. The equilibrium response (after subtraction from the response of the reference surface) of each experiment was used to create curves of analyte binding, which were both evaluated using Scatchard plots and fitted to a 1:1 steady-state affinity model using Origin7.0 software (OriginLab Corporation, USA).

\section{Glycan Microarray Analysis}

BclA was labeled with Alexa Fluor 488-TFP (Invitrogen, Carslbad, CA) according to the manufacturer's instructions and purified on a D-Salt polyacrylamide desalting column (Pierce, Rockford IL). Alexa-labeled BclA was used to probe the printed glycan arrays [17] following the standard procedure of Core $\mathrm{H}$ of the Consortium for Functional Glycomics (http://www.functionalglycomics.org/)

\section{Microcalorimetry}

Titration calorimetry experiments were performed using Microcal VP-ITC microcalorimeter (Microcal, Northampton, MA). All titrations were carried out in $0.1 \mathrm{M}$ Tris/ $\mathrm{HCl}$ buffer containing $3 \mu \mathrm{M} \mathrm{CaCl}_{2}, \mathrm{pH} 7.5$ at $25{ }^{\circ} \mathrm{C}$. Aliquots of $10 \mu \mathrm{l}$ of each carbohydrate at concentrations varying from 1.5 to $3 \mathrm{mM}$, dissolved in the same buffer, were added at 5 min intervals to the lectin solution present in the calorimeter cell. In the titrations, the protein 
concentration in the cell varied from 0.15 to $0.4 \mathrm{mM}$. The temperature of the cell was controlled to $25 \pm 0.1{ }^{\circ} \mathrm{C}$. Control experiments performed by injections of buffer in the protein solution yielded to insignificant heats of dilution. Integrated heat effects were analyzed by non-linear regression using a single-site binding model (Microcal Origin 7). Fitted data yielded the association constant $\left(K_{\mathrm{a}}\right)$ and the enthalpy of binding $(\Delta H)$. Other thermodynamic parameters, i.e. changes in free energy, $\Delta G$, and entropy, $\Delta S$, were calculated from the equation:

$$
\Delta G=\Delta H-T \Delta S=-R T \ln K_{\mathrm{a}}
$$

where $T$ is the absolute temperature and $R=8.314 \mathrm{~J} \cdot \mathrm{mol}^{-1} \cdot \mathrm{K}^{-1}$. Two to three independent titrations were performed for each ligand tested.

\section{Crystallization and data collection}

Lyophilized protein was dissolved in water $(15 \mathrm{mg} / \mathrm{ml})$ in the presence of $\alpha$-methylmannoside $(400 \mu \mathrm{g} / \mathrm{ml})$. Initial crystallisation conditions were screened using the complete Hampton Screens I and II (Hampton Research, Laguna Niguel, CA). Crystals in the form of thin plates appeared after several days in the presence of ammonium sulfate and PEG 3350, 5000MME, or 8000 . Crystals were cryo-cooled at $100 \mathrm{~K}$ after soaking them for as short a time as possible in glycerol $(15 \% \mathrm{v} / \mathrm{v})$ mixed with precipitant solution.. One such crystals was used to obtain a first set of diffraction data collected to $1.95 \AA$ resolution. It belongs to space group $\mathrm{C} 2$ with cell dimensions $a=153.7 \AA, b=49.6 \AA$ and $c=114.3 \AA$ and $\beta .=125.9^{\circ}$. Optimization of the initial crystallization conditions yielded crystals resembling small triangles from $2.5 \mu \mathrm{l}$ of $\mathrm{BclA}(14 \mathrm{mg} / \mathrm{ml})$ solution in complex with $\alpha$-methyl-mannoside (700 $\mu \mathrm{g} / \mathrm{ml}$ ) mixed with $2.5 \mu \mathrm{l}$ of reservoir solution consisting of $30 \%$ PEG 8000 and $0.2 \mathrm{M}$ ammonium sulfate. This crystal form belongs to space group C222 1 with cell dimensions $a=$ $50.0 \AA, b=185.7 \AA$ and $c=187.5 \AA$. After seeding, one thicker crystal was obtained and was cryo-cooled at $100 \mathrm{~K}$ after soaking for as short a time as possible in glycerol $(20 \% \mathrm{v} / \mathrm{v})$ mixed with precipitant solution. Diffraction data to $1.7 \AA$ resolution were obtained.

Both data sets were collected at ESRF (Grenoble, France) on stations ID14-2 and ID14-3 using an ADSC Q4R CCD detector (Quantum corp.) Diffraction images were integrated using MOSFLM [18] and scaled and converted to structure factors using the CCP4 program suite [19]. Statistics for the two data collections are shown in Table 5. 


\section{Structure solution and refinement}

A monomer of PA-IIL (PDB code 1GZT, with removal of ligands and water molecules) was used as a probe for molecular replacement for the monoclinic crystal form of BclA using the program MOLREP [20]. Five monomers were located and after an initial refinement cycle, the electron density maps of this complex showed glycerol instead of $\alpha$-Me-mannoside in the binding site. This structure was not further refined but was used as the search probe for the orthorhombic crystal, again giving five monomers in the asymmetric unit. After refinement, the electron density maps of this complex showed clear features corresponding to one $\alpha-\mathrm{Me}$ mannoside molecule and two calcium ions per monomer.

Crystallographic refinement was carried out with the program REFMAC [21] and manual model building with Coot [22]. Alternative conformations were constructed where necessary (with occupancies estimated from the refined relative $B$-factors of the conformations). The final model consists of all 630 residues with five sugar molecules, ten calcium ions, four sulfate ions, 0 glycerol molecules and 1164 water molecules with an $\mathrm{R}_{\text {crys }}$ of $16.9 \%$ and $\mathrm{R}_{\text {free }}$ of $20.3 \%$ to $1.7 \AA$ resolution. Coordinates have been deposited at the Protein Data Bank under code XXX. Molecular drawings were prepared using PyMOL [23].

\section{Results}

\section{Occurrence of lecB-like gene in Burkhoderia genomes}

The Burkholderia genus comprises more than 40 Burkholderia species [24], 12 of which have their genome sequenced or in the process of being sequenced. Amongst them, the Bcc is represented by several strains of $B$. cenocepacia and others. A similarity search based on the $l e c B$ sequence allowed the identification of genes coding for related proteins in several of these genomes, all of them corresponding to species both belonging to the Bcc complex and reported in CF isolates (Table S1 in supplementary material), namely B. cenocepacia, B. cepacia, B. ambifaria and B. dolosa. However, no lecB-like sequence could be found in the completed genomes of B. thailandensis, a soil inhabitant, or of B. mallei and B. pseudomallei, 
that are primary pathogens causing glanders in animals and melioidosis in humans, respectively. Surprisingly, in all genomes from Bcc species where it was identified, the lecBlike gene does not appear as a single copy, as previously observed in P. aeruginosa, $R$. solanacearum and C. violaceum but at the 3 '-terminus of several genes coding for proteins of various size (Table S1 in supplemental data).

The B. cenocepacia J2315 genome sequence consists of three chromosomal replicons and a small plasmid. Three lecB-related genes, with sizes of 384,732 and $816 \mathrm{bp}$, are present in the second chromosome and the corresponding gene products are referred to as BclA (129 aa without the initiating methionine), BclB (244 aa) and BclC (272 aa) (Figure 1A). A fourth gene with sequence similarities to $l e c B$ was identified on the third chromosome. This last gene is invalidated due to a frameshift, but in the genome of other Burkholderia species such as B. cepacia R18194-ATCC17660 (DOE) or B. spp. SAR-1, it could code for a protein of 289 and 296 amino acids, respectively.

In the present study, we focused on the analysis of BclA, the shortest protein encoded by a lecB-like gene in B. cenocepacia. This gene was identified in five strains of B. cenocepacia and one strain of B. ambifaria as well as an environmental sample from Sargassa sea that is likely to contain B. (ceno)cepacia. An alignment of the deduced amino acid sequences is shown in Figure 1B. All Burkholderia BclA protein sequences are very similar with 32\% identity with PA-IIL. The amino acids involved in the binding of the two calcium ions are conserved, as well as the C-terminus glycine that is involved in the architecture of the binding site through dimer formation. However, the BclA sequences are longer than the PA-IIL one with seven additional amino acids at the N-terminus and a nine amino acid insertion in the region corresponding to Asn85 of PA-IIL (all sequence numbering is given without initial methionines). The amino acids involved in sugar binding are partly conserved with a specificity loop consisting of Ala29-Ala30-Glu31 in BclA compared to Ser22-Ser23-Gly24 in PA-IIL. The higher affinity for mannose over fucose has been previously mainly attributed to the presence of alanine instead of serine at the first position of the specificity loop triplet in RS-IIL from R. solanacearum [15] and BclA would therefore be predicted to display some preference for mannose.

\section{Identification of BclA in B. cenocepacia}

Expression of native BclA lectin in B. cenocepacia strain J2315 was tested under different growing conditions, including cultivation on minimal and rich media with and without 
presence of iron and various sugars. Finally, four-days cultivation on rich media with the presence of D-mannose resulted in a reasonable amount of protein for MS analysis after purification. The results of a search using MASCOT based on the MALDI-MS and LCMS/MS analyses of prepared tryptic digest against NCBI database indicated the presence of protein BcenP_01004462 [Burkholderia cenocepacia PC184] (gi|84353445), which is a BclA ortholog from another B.c. strain. The search found 5 protein fragments matching the protein sequence with final score of 77 . In addition, a sixth matching fragment with a signal close to noise could be detected in the spectrum. The same result was obtained with search against a local database containing data from B. cenocepacia strain J2315 (data from The Sanger Institute, which are not included in NCBI sequence database). The search identified the BCAM0186 protein (chromosome 2, 216624:217013) that corresponds to BclA. The peptides identified in the BclA sequence are shown in Figure 2.

Cloning of lecB-like gene, production of recombinant BclA protein in E. coli and characterization.

Using the expression plasmid pRSETbcla, BclA was expressed in E. coli BL21(DE3) with a typical yield of about $40 \mathrm{mg}$ of the purified protein per liter of culture. The resulting protein was purified by affinity chromatography on mannose-agarose and ran as a sharp band of about $14 \mathrm{kDa}$ on SDS-PAGE. Mass spectroscopy analysis confirmed the molecular mass of $13764 \mathrm{Da}$, corresponding to the BclA amino acid sequence lacking the initial methionine residue. In contrast to the other PA-IIL-like proteins, size exclusion chromatography clearly demonstrated that BclA is a dimer in solution (Figure 3).

In order to further characterize the lectin, DLS and DSC experiments were performed (see supplementary data). Dynamic light scattering showed the hydrodynamic size of the lectin particle to be $5 \mathrm{~nm}$. This corresponds to the overall globular shape of the dimeric protein as observed in the crystal structure (see below). The thermal unfolding transition for BclA was measured using DSC to be at $87 \pm 0.5^{\circ} \mathrm{C}$ with a calorimetric heat change $(\Delta \mathrm{H})$ to van't Hoff heat change $(\Delta \mathrm{Hv})$ ratio about 0.5 (concentration normalization was carried out on a per mole of monomer basis). This also confirms presence of two unfolding units per mole of protein.

\section{Carbohydrate specificity of BclA}

A surface plasmon resonance binding assay was used to determine the affinity of BclA to sugars immobilized on the chip. The results show that whilst BclA does not interact with 
fucosylated and galactosylated surfaces, it does bind strongly to the mannosylatedpolyacrylamide surface. Figure 4A shows typical sensorgrams obtained after injection of different concentrations of $\mathrm{BclA}$. The association phase is rapid but the dissociation is very limited because of the density of mannoside available for binding. The shape of the sensorgrams suggests that the lectin probably undergoes some rebinding phenomena. The use of EDTA allows a rapid and total removal of the lectin for regeneration of the surface.

The lectin preference for different monosaccharides or monosaccharide derivatives was tested by their inhibition power on the binding of circulating BclA to the mannose surface. Figure 4B shows the sensorgrams obtained in the presence of increasing concentration of $\alpha$-methylD-mannoside ( $\alpha$ MeMan) preincubated with BclA prior to injection. A concentration of $30 \mu \mathrm{M}$ significantly inhibits the binding. The experimental binding curves obtained in the presence of competing sugar were fitted using a kinetic model for $1: 1$ binding (see supplementary data). Resonance units corresponding to steady-state equilibrium (Req) were calculated from fitted curves and taken as the amount of BclA bound to the chip surface in the presence of competing sugar. The values of IC50 for the different compounds were derived from such competition experiments.

The results show that D-mannose (Man) is an excellent inhibitor with an IC50 of $39 \mu \mathrm{M}$ (Table 1) whilst D-galactose (Gal) does not bind significantly to the lectin. Some inhibition effects are shown by the monosaccharides of the L-galacto series, such as L-fucose (Fuc), Darabinose (D-Ara) and L-galactose (L-Gal), but are two orders of magnitude weaker than Man, indicating that $\mathrm{BclA}$ has a high specificity for mannose. As classically observed in lectincarbohydrate interactions, the BclA lectin has higher affinity towards mannose derivatives with a hydrophobic aglycon group such as methyl ( $\alpha$ MeMan) or phenyl ( $\alpha$ BzMan) with IC50 values about 3 times smaller.

To take into account the accessibility of the BclA binding site, that could be modified when binding to the polymeric sugar on surface, SPR experiments were also conducted by evaluating the direct binding of ten monosaccharides ( $\alpha$ BzMan, $\alpha$ MeMan, Man, Fuc, D-Ara, methyl- $\alpha$-L-fucoside ( $\alpha$ MeFuc), Gal, L-galactose, N-acetyl-D-glucosamine (GlcNAc), Nacetyl-D-galactosamine (GalNAc)) to BclA immobilized on the surface. The sugars were tested at two different concentrations: $500 \mu \mathrm{M}$ and $25 \mathrm{mM}$. Whilst the mannose and mannosylated derivatives already showed site saturation at $500 \mu \mathrm{M}$ concentration (see 
supplementary data), for all the other sugars only partial saturation was observed (at $25 \mathrm{mM}$ concentration : Fuc-86\%, Ara-73\%, $\alpha$ MeFuc-45\%, L-gal-33\% and GalNAc, GlcNAc below $10 \%)$. Such results indicate that dissociation constants for these other tested sugars are weaker than millimolar values.

Since oligosaccharide specificity could be correlated to the possible function of the bacterial lectin in tissue recognition, binding to a broad spectrum glycan array was performed at the Consortium for Functional Genomics. The screening results show BclA to have a strict specificity for oligomannose type N-glycans, only binding to oligosaccharides with an $\alpha$ mannoside capped branch (Figure 5). The terminal disaccharides that are bound are $\alpha$ Man12Man, $\alpha$ Man1-3Man and $\alpha$ Man1-6Man, indicating that the specificity for the linkage is not strict. The lectin can also tolerate xylose substitution on the non-terminal mannose. Hybrid structures with the presence of $\mathrm{N}$-acetylglucosamine on one antenna are also recognized if terminal $\alpha$-mannoside residues are available on the second antenna.

\section{Thermodynamics of binding}

The three best ligands, i.e. mannose and its methyl and benzyl derivatives, were used to further characterize the interaction between $\mathrm{BclA}$ and its ligands by titration microcalorimetry, a method that is well suited for the characterization of protein-carbohydrate interactions [25]. A typical titration curve for $\alpha$ MeMan binding to BclA is shown in Figure 6A. Injection of the ligand yielded strong exothermic peaks in the first phase until reaching stoichiometry close to 1 . Fitting of the integrated peak values to theoretical models yielded the curves shown in Figure 6B. The fitting is not perfect for a classical one-site model, due to a clear increase in the exothermic reaction during the first 10 injections. Such a phenomenon can only be explained by the existence of several binding sites that either have different stoichiometry or have binding cooperativity. Since gel exclusion experiments demonstrated that $\mathrm{BclA}$ is a homodimer in solution, it is possible that binding of mannoside at one site increases the affinity of the other site. Indeed, a fitting procedure using a cooperative two-site model gave excellent agreement to the experimental data (Figure 6B).

Data obtained by averaging over three experiments for mannose and its derivatives are listed in Table 2. The cooperative binding models indicate the presence of a high affinity binding site with micromolar affinity that facilitates binding to a second site, with slightly lower affinity ( 7 to 12 micromolar depending on the ligand) but higher enthalpy. Since both sites do 
not have very different characteristics, the one-site model gives an "apparent" thermodynamic behavior that reflects the overall binding behavior. For the one-site model, BclA displays a very high affinity to mannose with a dissociation constant of $5 \mu \mathrm{M}$, i.e. a much stronger affinity than classically observed for plant or animal lectins. The methyl or benzyl derivatives display twice better affinity with a $\mathrm{K}_{\mathrm{d}}$ of $2.75 \mu \mathrm{M}$ for the interaction of BclA with $\alpha \mathrm{MeMan}$. This micromolar affinity is due both to a strong enthalpy of binding with $\Delta H$ values ranging between -23 to $-27 \mathrm{~kJ} / \mathrm{mol}$ and a favorable entropy of binding with $T \Delta S$ between 3 and 9 $\mathrm{kJ} / \mathrm{mol}$. The more favorable entropy displayed by the mannose derivatives may be due to the limitation of flexibility by blocking the anomeric equilibrium. This favorable entropy of binding is unusual in protein-carbohydrate interaction but has been reported in this calciumdependent family of bacterial lectins and is attributable to the involvement of the two calcium ions in sugar binding [26, 27].

\section{Crystal structure of BclA complexed with $\alpha$-Me-mannoside}

BclA was crystallized in presence of $\alpha$ MeMan and crystals were obtained after a few days in the presence of ammonium sulfate and PEG, in both monoclinic C2 and orthorhombic C222 space groups. The X-ray structure of the $\mathrm{C} 2$ form was determined by molecular replacement using the PA-IIL structure as the probe but was not refined further as no ligand was observed in the binding site. The $\mathrm{C} 222_{1}$ form structure, diffracting to $1.7 \AA$ resolution, was in turn determined using the $\mathrm{C} 2$ form coordinates from the first molecular replacement (Table 3). The asymmetric unit contains five BclA monomers, corresponding to 2 dimers (on a pseudo 2-fold axis) and a half dimer (forming a dimer by a crystallographic 2-fold axis). The N-terminal extremities exhibit disorder for the first 8 amino acids of chain A and the first residue of chain $\mathrm{C}$ that could not therefore be included in the final model. The overall topologies of BclA and PA-IIL are very similar with a nine-stranded antiparallel $\beta$-sandwich consisting of two sheets of four and five strands, respectively. Dimerisation is created by strong complementary packing of the hydrophobic curved $\beta$-sheet to its counterpart and via sheet extension (Figure 7A). This is the first description of a dimeric form for a bacterial lectin dependent on two calcium ions, with all structures previously reported adopting a tetrameric organization.

Each BclA monomer is associated with two calcium ions and one mannose residue, the electron density of which is shown in Figure 7B. The two ions are located close together, 3.73 $(+/-0.2) \AA$ apart, with a classical seven ligand coordination, mainly involving one loop via the side chains of Glu109, Asp113, Asp115, Asn117 and Asp118 (Figure 7C and Table S2 in 
supplemental data). A second loop is involved through the side chain of Asn28. In addition, the acidic group of the C-terminus Gly128 of the other monomer, which is involved in the head-to-tail interaction, also participates in the coordination of the calcium ions.

The $\alpha$ MeMan molecule participates directly in the coordination of the calcium ions with hydroxyl groups $\mathrm{O} 2, \mathrm{O} 3$ and $\mathrm{O} 4$, in a similar fashion to the PA-IIL/Man complex [28]. The O2, O3, O4 and O6 hydroxyl groups are also involved in hydrogen bonds with acidic amino acids Asn28, Ala30, Glu31, Asp110, Asp113, Asp115, Asp118 and with the terminal carboxylate of Gly128 of the neighboring monomer (Figure 7C and Table S2 in supplemental data). Two types of hydrophobic contacts can be observed. Firstly, the methyl group at the anomeric position is close to the methyl group of Ala30 and His112. This histidine has no equivalent in the other related bacterial lectins and seems to play a special role. Analysis of the electron density indicates that His 112 adopts a double conformation with approximately $50 / 50$ occupancy in all of the 5 binding sites. In one orientation it creates hydrophobic contacts with the C5 and C6 atom of the Man hydroxymethyl group. In this conformation, the ND1 nitrogen of His112 can give a hydrogen bond to the side chain of Asp110 while its CE1 creates hydrophobic contact with CG of Glu31, therefore creating a rather "close" conformation of the binding site (Figure 7D). In the other conformation, the same histidine adopts a different side chain orientation and makes hydrophobic contact to the hydrophobic faces of mannose (C3 and C5) and to methyl group at $\mathrm{C} 1$. This is the first evidence of flexibility in the binding site a Ca-dependent bacterial lectin.

\section{Discussion}

\section{Novel quaternary arrangement in two Ca-dependent bacterial lectins.}

The first crystal structure of a soluble lectin dependent upon two calcium ions has been reported from Pseudomonas aeruginosa PA-IIL [13]. Later, two related structures have been described from similar proteins present in two opportunistic bacteria: RS-IIL from Ralstonia solanacearum [15] and CV-IIL from Chromobacterium violaceum [14]. The three proteins have very similar sequences (60 to $70 \%$ identity), with identical fold and tetrameric arrangement. The BclA protein belongs to the same family of proteins but displays clear differences to the lectins mentioned above. The central $\beta$-sandwich monomer fold is conserved but variations in loop conformation can be observed (Figure 8A). The most visible 
difference is the extension of the N-terminal, with seven additional amino acids for BclA for which electron density is clearly defined except in monomer A. The loop between $\beta$-strands 7 and 8 is also much longer in BclA thanks to an insertion of nine amino acids.

The differences in peptide sequence also influence the oligomeric arrangement. BclA is a dimer in solution as well as in the crystal structure. Superposition of dimeric BclA on tetrameric PA-IIL (Figure 8B) shows that the additional N-terminal amino acids (particularly Arg9) and the longer loop (particularly Pro98) would not allow the creation of the dimerdimer interface that is observed in the other structures of the family. A thorough examination of the contact region also reveal that bulky amino acids such as Arg85 create steric conflicts when trying to build a tetramer by homology modeling.

\section{Structural basis for mannose specificity and possible biological functions}

The three lectins previously characterized from opportunistic bacteria have a rather large range of specificity, each binding to several monosaccharides. Their main stereochemical requirement is the presence of one axial hydroxyl group located next to two equatorial ones, a sequence that is present in L-galacto sugars (O4 axial and O3, O2 equatorial) such as Lgalactose, L-fucose, D-arabinose and D-fructopyranose but also in D-manno sugars (O2 axial and $\mathrm{O} 3, \mathrm{O} 4$ equatorial) such as D-mannose $[12,15,29]$. However, the specificity is correlated to the nature of a stretch of three amino acids located in the so-called "specificity loop". It has been established that the sequence Ser22-Ser23-Gly24 (in PA-IIL) does not favor the binding of mannose whereas the Ala-Ala-Asn series of RS-IIL does. A comparison showed that in PA-IIL, Ser22 makes a hydrogen bond to the side chain of Asp96, preventing it from binding to $\mathrm{O} 6$ of mannose. We have recently demonstrated that by mutating the specificity loop residues the sugar specificity can be engineered, with the Ser22Ala PA-IIL mutant binding more strongly to mannose than to fucose [30].

The situation is very different in BclA since the protein has a strict preference for mannoside. The competition experiments performed using SPR indicate some inhibition power for fucose but microcalorimetry experiments with the same monosaccharide and SPR experiments using direct binding of BclA to the fucosylated surface did not show any signal, indicating that the binding is at least one thousand times weaker than for mannose. Indeed, the triplet in the 
specificity loop is Ala29-Ala30-Glu31 which therefore allows O6 of mannose to form a strong hydrogen bond to the side chain of Asp110 (Figure 8D). Furthermore, it seems that fucose binding is excluded because His112, only present in BclA, stacks favorably against C6 or $\mathrm{C} 1$ of mannose (depending upon side chain orientation), but would collide with the $\mathrm{O} 1$ of $\alpha$-fucose (Figure 8C).

BclA also has further differences with the other bacterial lectins when considering the interaction thermodynamics. All of the calcium-dependent soluble bacterial lectins studied up till now display micromolar affinity for monosaccharides [26], with a strong enthalpy of binding and a small favorable entropy, an unusual behavior for protein-carbohydrate interactions that has been correlated to the presence of calcium [27]. All of the experiments could be fitted to a one-site model, which is in agreement with the crystal structures. BclA also displays strong affinity for mannoside but it was not possible to fit the experimental data using a one-site model. In the case of BclA, only once cooperativity between the two binding sites of the monomers was included in the model was a good agreement between fitted and experimental curves obtained. This behavior can be correlated to the unusual flexibility of His 112 in the binding site and/or to the unusually long loop in the 90-100 sequence region that only exists in BclA. Indeed, this loop is located very close to the His 112 loop of the other monomer and it can be postulated that binding of mannose in one site alters the dynamics of one loop which in turn affects the second binding site. A molecular dynamics study will be performed for a better understanding of this unusual cooperativity mechanism.

\section{Conclusions}

Strong interest has been shown in bacterial lectins recently because of their novel structure and carbohydrate binding modes, their high affinity for carbohydrate ligands and their possible role in host recognition, in adhesion and in biofilm formation. A series of such lectins, all based on the sequence of the PA-IIL lectin, has been identified and subsequently studied from several bacteria. They all have a common fold and tetrameric structure but different sugar specificities whilst being dependent upon a special two-calcium coordination. The surprising discovery of several such lectins also in the genome of Burkholderia cenocepacia led to the characterization (structurally and thermodynamically) of the smallest gene product, BclA. The role of the lectin in bacterial infection has to be elucidated but the present work yielded to significant progress in elucidation of structure, affinity and specificity of this new lectin. 
The studies presented here show this lectin to have a core fold identical to PA-IIL, but tetramer formation is hindered because of the presence of additional loops. The BclA lectin also differs with an apparent novel cooperative binding across the dimer, compared to the purely single-site binding of PA-IIL and its family. BclA is indeed a member of the PA-IIL lectin family, dependent on two calcium ions, with a core beta-sheet structure but is the first member to associate only as a dimer and to present site cooperativity. Its specificity is for mannoside sugars and the glycan array experiment shows specificity for oligomannose-type oligosaccharides that are present on human glycoproteins.

\section{Acknowledgements}

This research is part of E.L. and L.M. Ph.D. thesis, who are supported Conseil Régional Rhône-Alpes (Cluster 10), and by the Ministry of Education (MSM0021622413, MSM0021622415, LC06030) and Grant agency (GA303/06/570) of the Czech Republic. The glycan array resources were provided by the Consortium for Functional Glycomics Grant number GM62116. Travel and visits between NCBR and CERMAV are supported by a BARRANDE exchange program (M.W. \& A.I.) and financial help is gratefully acknowledged from the French cystic fibrosis association 'Vaincre la Mucoviscidose'. The authors wish to thank Ms Catherine Gautier for excellent technical help. We thank the ESRF, Grenoble, for access to synchrotron data collection facilities. 


\section{References}

1 Mahenthiralingam, E. and Vandamme, P. (2005) Taxonomy and pathogenesis of the Burkholderia cepacia complex. Chron. Respir. Dis. 2, 209-217

2 Chiarini, L., Bevivino, A., Dalmastri, C., Tabacchioni, S. and Visca, P. (2006) Burkholderia cepacia complex species: health hazards and biotechnological potential. Trends in microbiology. 14, 277-286

3 Govan, J. R. and Deretic, V. (1996) Microbial pathogenesis in cystic fibrosis: mucoid Pseudomonas aeruginosa and Burkholderia cepacia. Microbiol. Rev. 60, 539-574

4 Lyczak, J. B., Cannon, C. L. and Pier, G. B. (2002) Lung infections associated with cystic fibrosis. Clin Microbiol Rev. 15, 194-222

5 Saiman, L. and Siegel, J. (2004) Infection control in cystic fibrosis. Clin. Microbiol. Rev. 17, 57-71

6 Riedel, K., Hentzer, M., Geisenberger, O., Huber, B., Steidle, A., Wu, H., Hoiby, N., Givskov, M., Molin, S. and Eberl, L. (2001) N-acylhomoserine-lactone-mediated communication between Pseudomonas aeruginosa and Burkholderia cepacia in mixed biofilms. Microbiology (Reading, England). 147, 3249-3262

7 Eberl, L. and Tummler, B. (2004) Pseudomonas aeruginosa and Burkholderia cepacia in cystic fibrosis: genome evolution, interactions and adaptation. Int. J. Med. Microbiol. 294, 123-131

8 Gilboa-Garber, N. (1982) Pseudomonas aeruginosa lectins. Methods Enzymol. 83, 378385

9 Imberty, A., Wimmerova, M., Sabin, C. and Mitchell, E. P. (2006) Structures and roles of Pseudomonas aeruginosa lectins. In Protein-Carbohydrate Interactions in Infectious Disease (Bewley, C., ed.). pp. 30-48, The Royal Society of Chemistry, Cambridge

10 Tielker, D., Hacker, S., Loris, R., Strathmann, M., Wingender, J., Wilhelm, S., Rosenau, F. and Jaeger, K.-E. (2005) Pseudomonas aeruginosa lectin LecB is located in the outer membrane and is involved in biofilm formation. Microbiology (Reading, England). 151, 1313-1323

11 Sudakevitz, D., Imberty, A. and Gilboa-Garber, N. (2002) Production, properties and specificity of a new bacterial L-fucose- and D-arabinose-binding lectin of the plant aggressive pathogen Ralstonia solanacearum and its comparison to related plant and microbial lectins. J. Biochem. 132, 353-358

12 Zinger-Yosovich, K., Sudakevitz, D., Imberty, A., Garber, N. C. and Gilboa-Garber, N. (2006) Production and properties of the native Chromobacterium violaceum fucosebinding lectin (CV-IIL) compared to homologous lectins of Pseudomonas aeruginosa (PAIIL) and Ralstonia solanacearum (RS-IIL). Microbiology (Reading, England). 152, 457 463

13 Mitchell, E., Houles, C., Sudakevitz, D., Wimmerova, M., Gautier, C., Pérez, S., Wu, A. M., Gilboa-Garber, N. and Imberty, A. (2002) Structural basis for oligosaccharidemediated adhesion of Pseudomonas aeruginosa in the lungs of cystic fibrosis patients. Nature Struct. Biol. 9, 918-921

14 Pokorná, M., Cioci, G., Perret, S., Rebuffet, E., Kostlánová, N., Adam, J., Gilboa-Garber, N., Mitchell, E. P., Imberty, A. and Wimmerová, M. (2006) Unusual entropy driven affinity of Chromobacterium violaceum lectin CV-IIL towards fucose and mannose. Biochemistry. 45, 7501-7510 
15 Sudakevitz, D., Kostlanova, N., Blatman-Jan, G., Mitchell, E. P., Lerrer, B., Wimmerova, M., Katcof, f. D. J., Imberty, A. and Gilboa-Garber, N. (2004) A new Ralstonia solanacearum high affinity mannose-binding lectin RS-IIL structurally resembling the Pseudomonas aeruginosa fucose-specific lectin PA-IIL. Mol. Microbiol. 52, 691-700

16 Govan, J. R., Brown, P. H., Maddison, J., Doherty, C. J., Nelson, J. W., Dodd, M., Greening, A. P. and Webb, A. K. (1993) Evidence for transmission of Pseudomonas cepacia by social contact in cystic fibrosis. Lancet. 342, 15-19

17 Blixt, O., Head, S., Mondala, T., Scanlan, C., Huflejt, M. E., Alvarez, R., Bryan, M. C., Fazio, F., Calarese, D., Stevens, J., Razi, N., Stevens, D. J., Skehel, J. J., van Die, I., Burton, D. R., Wilson, I. A., Cummings, R., Bovin, N., Wong, C. H. and Paulson, J. C. (2004) Printed covalent glycan array for ligand profiling of diverse glycan binding proteins. Proc. Natl. Acad. Sci. USA. 101, 17033-17038

18 Leslie, A. G. W. (1992) Recent changes to the MOSFLM package for processing film and image plate data. Joint CCP4 + ESF-EAMCB Newsletter on Protein Crystallography. 26

19 Collaborative Computational Project Number4(1994) The CCP4 suite: programs for protein crystallography. Acta Crystallogr., 760-763

20 Vagin, A. and Teplyakov, A. (1997) MOLREP: an automated program for molecular replacement. J. Appl. Cryst. 30, 1022-1025

21 Murshudov, G. N., A.A.Vagin and E.J.Dodson. (1997) Refinement of macromolecular structures by the maximum-likelihood method. Acta Crystallogr. D53, 240-255

22 Emsley, P. and Cowtan, K. (2004) Coot: Model-Building Tools for Molecular Graphics. Acta Crystall. D Biol. Crystall. 60, 2126-2132

23 Kraulis, P. (1991) Molscript: A program to produce both detailed and schematic plots of protein structures. J. Appl. Crystallogr. 24, 946-950

24 Vandamme, P., Govan, J. R. and LiPuma, J. (2007) Diversity and role of Burkholderia spp. In Burkholderia. Molecular Biology and Genomics (Coenye, T. and Vandamme, P., eds.). pp. 1-28, Horizon Bioscience, Wymondham, UK

25 Dam, T. K. and Brewer, C. F. (2002) Thermodynamic studies of lectin-carbohydrate interactions by isothermal titration calorimetry. Chem. Rev. 102, 387-429.

26 Imberty, A., Mitchell, E. P. and Wimmerová, M. (2005) Structural basis for high affinity glycan recognition by bacterial and fungal lectins. Curr. Opin. Struct. Biol. 15, 525-534

27 Mitchell, E. P., Sabin, C., Šnajdrová, L., Pokorná, M., Perret, S., Gautier, C., Hofr, C., Gilboa-Garber, N., Koca, J., Wimmerová, M. and Imberty, A. (2005) High affinity fucose binding of Pseudomonas aeruginosa lectin PA-IIL: $1.0 \AA$ resolution crystal structure of the complex combined with thermodynamics and computational chemistry approaches. Proteins: Struct. Funct. Bioinfo. 58, 735-748

28 Loris, R., Tielker, D., Jaeger, K.-E. and Wyns, L. (2003) Structural basis of carbohydrate recognition by the lectin LecB from Pseudomonas aeruginosa. J. Mol. Biol. 331, 861-870

29 Sabin, C., Mitchell, E. P., Pokorná, M., Gautier, C., Utille, J.-P., Wimmerová, M. and Imberty, A. (2006) Binding of different monosaccharides by lectin PA-IIL from Pseudomonas aeruginosa: Thermodynamics data correlated with X-ray structures. FEBS Lett. 580, 982-987

30 Adam, J., Pokorna, M., Sabin, C., Mitchell, E. P., Imberty, A. and Wimmerova, M. (2007) Engineering of PA-IIL lectin from Pseudomonas aeruginosa - Unravelling the role of the specificity loop for sugar preference. BMC Struct. Biol. 736 
31 Laskowski, R. A., MacArthur, M. W., Moss, D. S. and Thornton, J. M. (1993) PROCHECK: a program to check the stereochemical quality of protein structures. J. Appl. Crystallogr. 26, 283-291

32 Vriend, G. (1990) WHAT IF: A molecular modeling and drug design program. J. Mol. Graph. 8, 52-56 
Table 1. IC50 obtained by SPR for the inhibition of binding of BclA to polymeric mannose surface.

\begin{tabular}{ccc}
\hline Inhibitor & IC50 & Potency \\
\hline aMeMan & $18.2 \mu \mathrm{M}$ & 2.1 \\
$\alpha$ BenzMan & $14.4 \mu \mathrm{M}$ & $\mathbf{1}$ \\
D-mannose & $\mathbf{3 9 . 0} \boldsymbol{\mu M}$ & 0.018 \\
D-arabinose & $2100 \mu \mathrm{M}$ & 0.017 \\
L-fucose & $2300 \mu \mathrm{M}$ & 0.003 \\
L-galactose & $12600 \mu \mathrm{M}$ & 0.001 \\
$\alpha$ MeFuc & $20900 \mu \mathrm{M}$ & - \\
D-galactose & $\mathrm{ND}$ & \\
\hline
\end{tabular}


Table 2. Microcalorimetry data. All values are averaged over three experiments (two for the mannose complex). Errors due to the fitting procedure are less than $10 \%$ for the one-site model and less than $15 \%$ for the cooperative two-site model. Standard deviations when averaging are below these values.

\begin{tabular}{|c|c|c|c|}
\hline & Man & $\alpha$ MeMan & $\alpha$ BenzMan \\
\hline & \multicolumn{3}{|c|}{ Cooperative two-site model (per dimer) } \\
\hline $\mathrm{K}_{\mathrm{a} 1} / \mathrm{K}_{\mathrm{a} 2}\left(10^{3} \mathrm{M}^{-1}\right)$ & $300 / 80.6$ & $525 / 118$ & $618 / 141$ \\
\hline $\mathrm{K}_{\mathrm{d} 1} / \mathrm{K}_{\mathrm{d} 2}\left(10^{-6} \mathrm{M}\right)$ & $3.3 / 12.4$ & $2.7 / 7.8$ & $1.6 / 7.1$ \\
\hline$-\Delta \mathrm{G}_{1} /-\Delta \mathrm{G}_{2}(\mathrm{~kJ} / \mathrm{mol})$ & $-31.3 /-28.0$ & $-32.7 /-29.0$ & $-33.0 /-29.4$ \\
\hline$-\Delta \mathrm{H}_{1} /-\Delta \mathrm{H}_{2}(\mathrm{~kJ} / \mathrm{mol})$ & $-26.0 /-31.8$ & $-20.8 /-28.4$ & $-22.9 /-28.5$ \\
\hline $\mathrm{T} \Delta \mathrm{S}_{1} / \mathrm{T} \Delta \mathrm{S}_{2}(\mathrm{~kJ} / \mathrm{mol})$ & $5.3 /-3.8$ & $11.9 / 0.6$ & $10.1 / 0.9$ \\
\hline \multicolumn{4}{|c|}{ One-site model (per monomer) } \\
\hline $\mathrm{K}_{\mathrm{a}}\left(10^{3} \mathrm{M}^{-1}\right)$ & 194 & 364 & 361 \\
\hline $\mathrm{K}_{\mathrm{d}}\left(10^{-6} \mathrm{M}\right)$ & 5.15 & 2.75 & 2.80 \\
\hline $\mathrm{n}$ & 0.91 & 0.83 & 0.86 \\
\hline$-\Delta \mathrm{G}(\mathrm{kJ} / \mathrm{mol})$ & 30.2 & 31.8 & 31.7 \\
\hline$-\Delta \mathrm{H}(\mathrm{kJ} / \mathrm{mol})$ & 27.0 & 23.0 & 24.2 \\
\hline $\mathrm{T} \Delta \mathrm{S}(\mathrm{kJ} / \mathrm{mol})$ & 3.2 & 8.8 & 7.5 \\
\hline
\end{tabular}


Table 3. Data collection and refinement statistics

\begin{tabular}{lll}
\hline Data collection & Monoclinic form & Orthorombic form \\
Beamline & ID14-2 & ID14-3 \\
Wavelength $(\AA)$ & 0.933 & 0.934 \\
Resolution $(\AA)$ & $31.81-1.95(2.00-1.95)$ & $33.63-1.70(1.74-1.70)$ \\
Space group & $\mathrm{C} 2$ & $\mathrm{C} 222_{1}$ \\
Cell dimensions : & & \\
a, b, c $(\AA)$ & $153.7,49.6,114.3$ & 50.0185 .7187 .5 \\
$\beta\left({ }^{\circ}\right)$ & 125.9 & 702443 \\
Measured reflections & 180948 & $96348(6680)$ \\
Unique reflections & $50938(3737)$ & $7.3(7.1)$ \\
Average multiplicity & $3.6(3.6)$ & $99.9(99.7)$ \\
Completeness $(\%)$ & $99.5(99.3)$ & $19.1(3.5)$ \\
M I/ $(\mathrm{I})$ & $13.6(2.8)$ & $7.3(43.3)$ \\
$\mathrm{R}_{\text {Merge }}(\%)$ & $9.6(48.1)$ &
\end{tabular}

\section{Refinement}

Resolution range $(\AA)$

$R_{\text {crys }}$ (observation)

$0.169(0.242)$

$R_{\text {free }}$ (observation)

$0.203(0.294)$

Average $\mathrm{B}_{\text {iso }}(\AA)$

Chain / protein / sugar / calcium
A / $15.9 / 12.7 / 10.9$
$\mathrm{B} / 15.1 / 16.0 / 11.5$
C / $15.2 / 14.1 / 12.0$
$\mathrm{D} / 14.4$ / 10.5 / 9.2
E / $15.1 / 13.4 / 10.8$ $32.5 / 34.3$

Water / sulfate

RMS Deviation from ideality

Bonds ( $)$

0.015

Angles (degrees)

Ramachandran plot statistics

Residues in favoured regions (\%)

99.6

Residues in disallowed regions (\%)

0.4 (Asp2 of E and D)

Values in parenthesis refer to the highest resolution shell.

$\mathrm{R}_{\text {Merge }}=\sum|I-<\mathrm{I}>| / \sum<\mathrm{I}>$, where $\mathrm{I}=$ observed intensity.

Geometry analyses were performed by PROCHECK [31] and WHATIF [32]. 


\section{Figure legends}

Figure 1. A. Schematic representation of PA-IIL-like containing proteins in B. cenocepacia. B. Alignment of BclA sequences from different strains with PA-IIL sequences. Strictly conserved amino acids are represented with black background. Amino acids of PA-IIL involved in calcium binding are labeled with * and those involved in sugar binding with 0 ,

Figure 2. Peptides identified in the tryptic digest of a native protein isolated from $B$. cenocepacia strain J2315, which corresponds to the BclA lectin using MALDI-MS and LCMS/MS analyses. Five fragments directly identified by the MASCOT search are represented on black background with a double bar indicating the last amino acid. The sixth fragment close to signal noise is represented with grey background.

Figure 3. Size exclusion chromatogram of BclA on Superose 12 column. Using molecular weight standards at the same running conditions, the molecular mass of the BclA protein was estimated to be $28 \mathrm{kDa}$ corresponding to a dimer in solution.

Figure 4. SPR sensorgrams representing binding of BclA on polymeric mannosylated chips. A. Concentration-dependent binding of BclA to the chips from $0.0625 \mathrm{mg} / \mathrm{ml}$ (lowest curve) to $0.125,0.25,0.5$ and $1 \mathrm{mg} / \mathrm{ml}$ (highest curve). B. Inhibition curves obtained from different concentration of $\alpha \mathrm{MeMan}$ from $0 \mu \mathrm{M}$ (highest curve) to $1.95,3.9,7.8,15.6,31.25,62.6,125$ and $250 \mu \mathrm{M}$ (lowest curve). C. Percentage of inhibition measured for different monosaccharides and sugar derivatives.

Figure 5. Glycan array analysis of BclA as measured by fluorescence intensity. All glycans yielding to a ratio signal/noise larger than 1.5 have been represented. Missing area corresponds to series of glycans with no significant labeling. Complete results including comprehensive oligosaccharide list (Plate Array Version 3) are available from the Consortium of Functional Glycomics (http://www.functionalglycomics.org/). Abbreviations for spacer as follow: $\mathrm{SP} 1,-\mathrm{O}(\mathrm{CH} 2) 2 \mathrm{NH}(\mathrm{O})(\mathrm{CH} 2) 5 \mathrm{NHC}(\mathrm{O})(\mathrm{CH} 2) 5 \mathrm{NHC}(\mathrm{O})-\mathrm{Biotin} ; \mathrm{SP} 2,-\mathrm{O}(\mathrm{CH} 2) 3 \mathrm{NH}-$ $\mathrm{CO}(\mathrm{CH} 2) 5 \mathrm{NH}-\mathrm{Biotin}$. 
Figure 6. Titration microcalorimetry of $\alpha \operatorname{MeMan}(3 \mathrm{mM})$ binding to BclA $(0.39 \mathrm{mM})$ in $100 \mathrm{mM}$ Tris buffer, $\mathrm{pH} 7.5$ with $3 \mu \mathrm{M} \mathrm{CaCl}_{2}$ at $25^{\circ} \mathrm{C}$. Top, data for 30 automatic injections of $10 \mu \mathrm{L}$ of $\alpha \mathrm{MeMan}$ each intor the BclA-containing cell. Bottom, plot of the total heat released as a function of molar ratio for dimeric BclA (squares). The dashed line represents the best fit for a one-site model and the dashed lined the best fit for a cooperative two-site model.

Figure 7. A. Orthographic representation of ribbon diagram of $\mathrm{BclA}$ dimer complexed with $\alpha$ MeMan (sticks) and calcium (spheres). B. Electron density $\left(1 \sigma=\right.$ electron per $\left.\AA^{2}\right)$ around the ligand and the two alternative conformation of His112. C. Details of the bindings site with coordination bonds represented by solid pink lines and hydrogen bonds by dashed green lines. D. Protein surface of the binding site generated by the two possible orientations of His112.

Figure 8. Comparison of crystal structures of PA-IIL/fucose from Pseudomonas aeruginosa (code 1GZT) and BclA/ $\alpha$ MeMan from B. cenocepacia. A. superposition of the BclA dimer (magenta) and PA-IIL equivalent monomers (blue). B. Superposition of the BclA dimer on the PA-IIL tetramer and its protein surface. C. Superposition of the binding sites. D. Comparison of the binding site surface with His 112 of BclA in the "close" conformation. 
Biochemical Journal Immediate Publication. Published on 16 Jan 2008 as manuscript BJ20071276

B. cenocepacia J2315

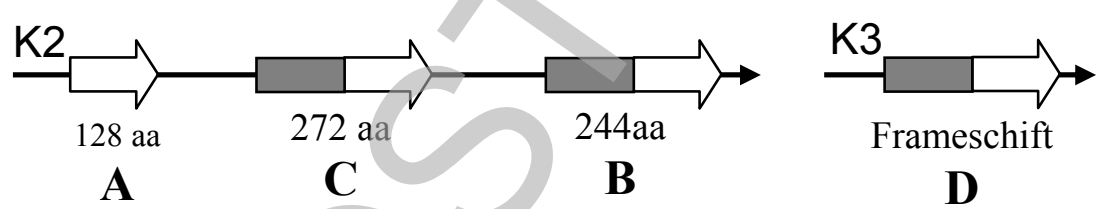

B. ceno-J2315

B. ceno-AU1054

B. ceno-MCO - 3

B.ceno-PC184

B. ceno-HI2424

B . amb-MC4 0- 6

B. sp 383

Burkholderia_SAR-1

PA-IIL

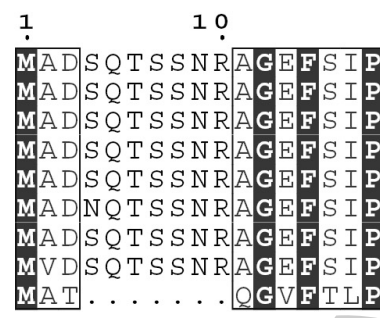

20

$30 \quad 40$

50

60

P T T F

4050

B.ceno-J 2315

B. ceno-AU1054

B. ceno-MCO - 3

B. ceno-PC184

B. ceno-HI2424

B . amb-MC4 0- 6

B. sp 383

Burkholderia SAR-1

PA-IIL

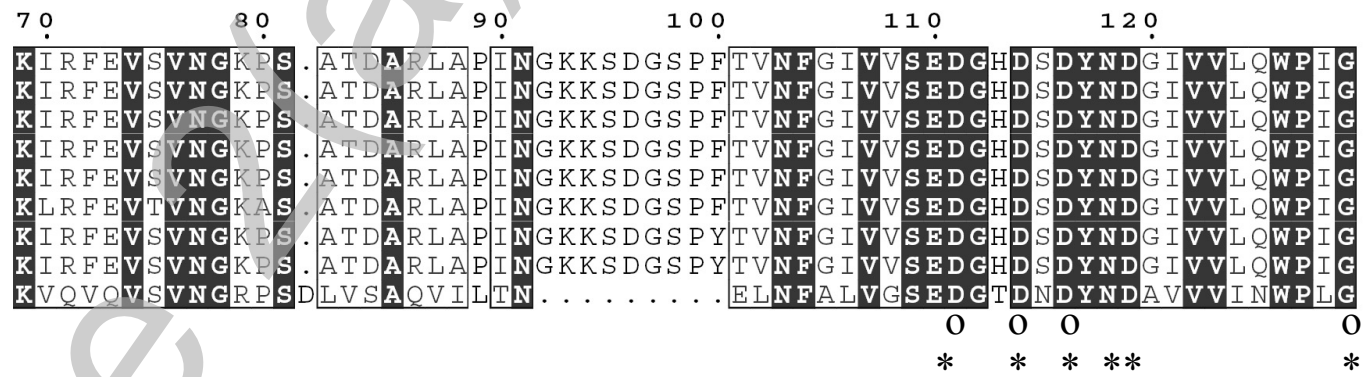

Figure 1

Licenced copy. Copying is not permitted, except with prior permission and as allowed by law.

(C) 2008 The Authors Journal compilation (C) 2008 Biochemical Society 


\section{ADSQTSSNRA GEFSIPPNTD FRAIFFANAA EQQHIKIFIG DSQEPAAYHK \\ 51 LTTRDGPREA TLNSGNGKIR FEVSVNGKPS ATDARLAPIN GKKSDGSPFT}

\section{VNEGIVVSED GHDSDYNDGI VVLQWPIG}




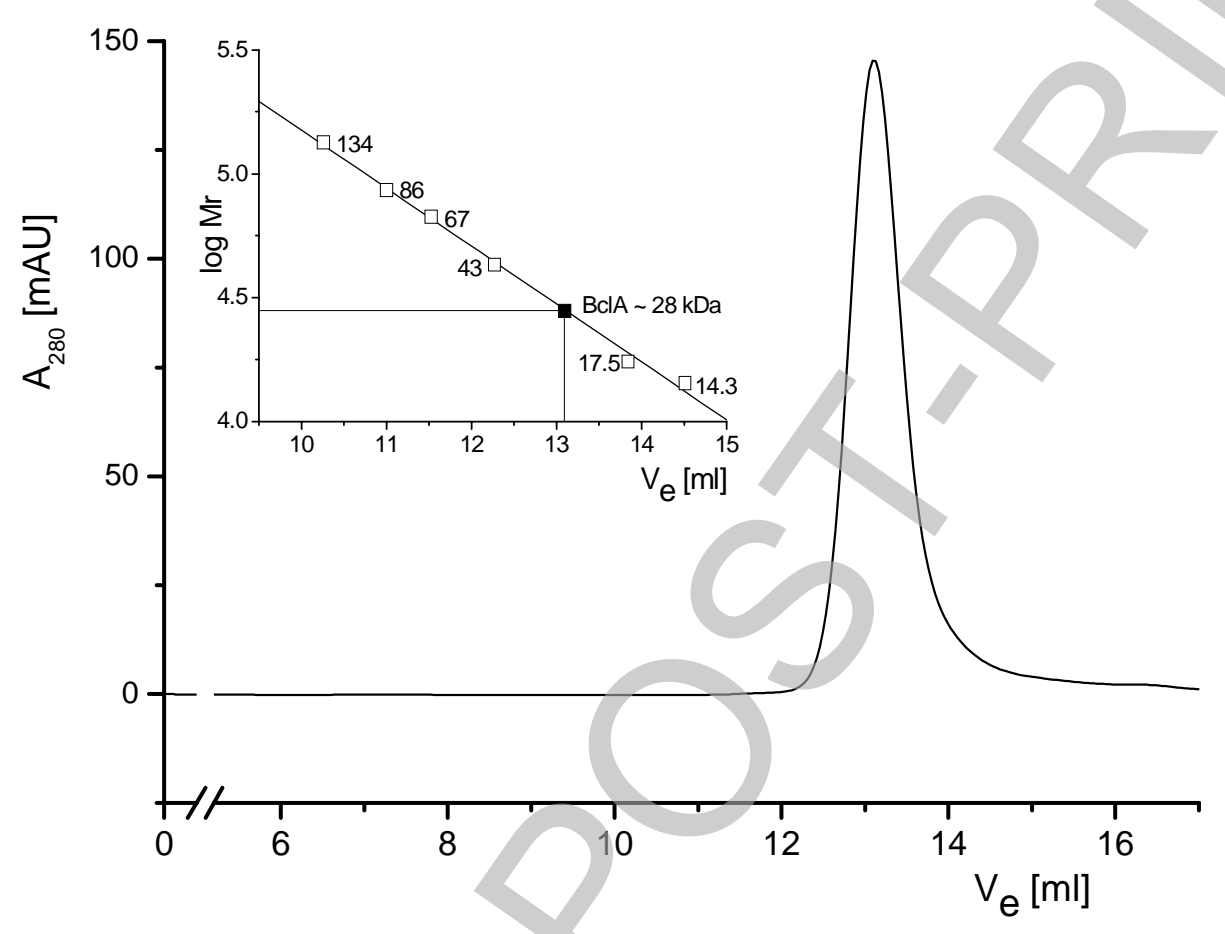

Figure 3

Licenced copy. Copying is not permitted, except with prior permission and as allowed by law. (C) 2008 The Authors Journal compilation (C) 2008 Biochemical Society 

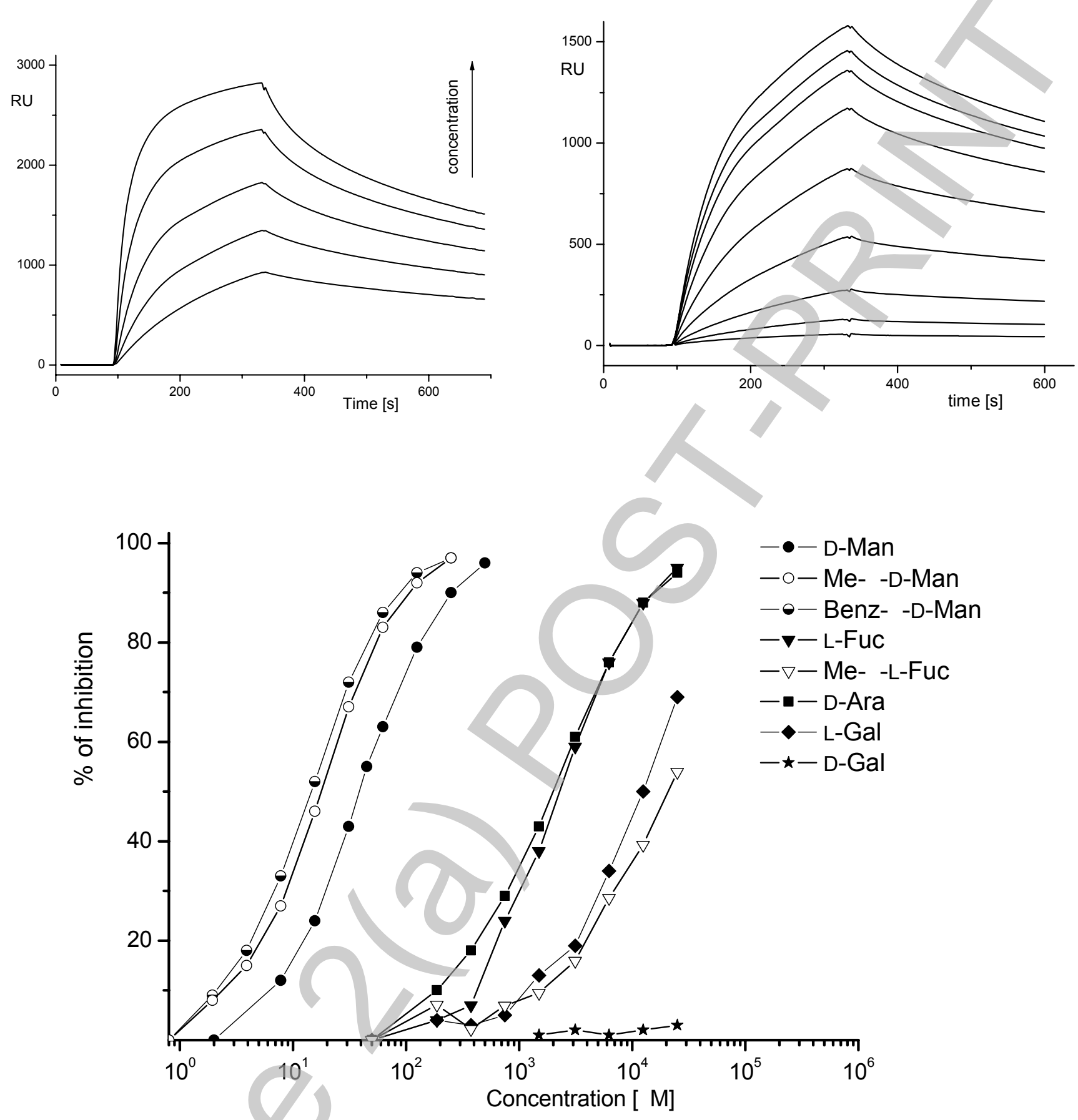


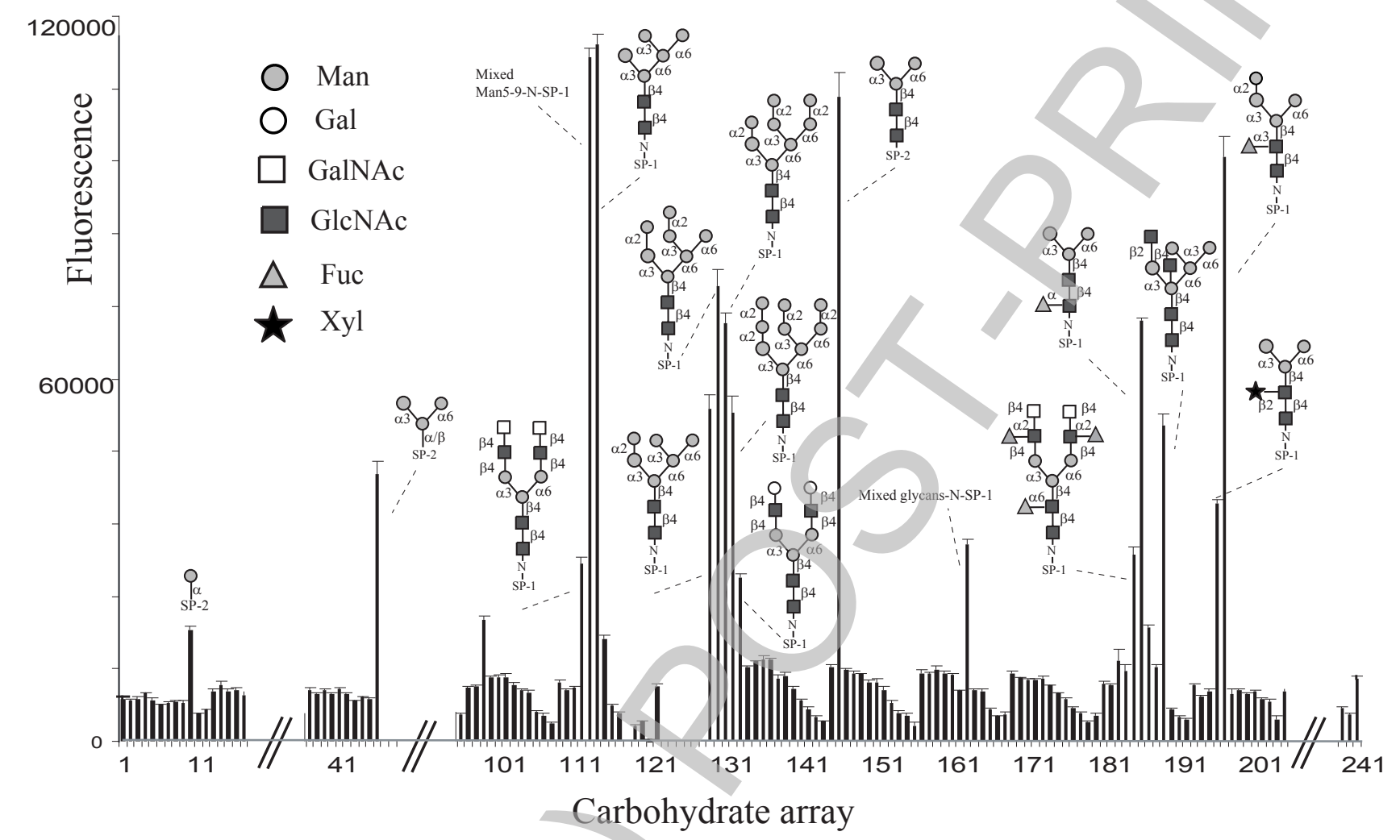

Figure 5

Licenced copy. Copying is not permitted, except with prior permission and as allowed by law. (c) 2008 The Authors Journal compilation (c) 2008 Biochemical Society 


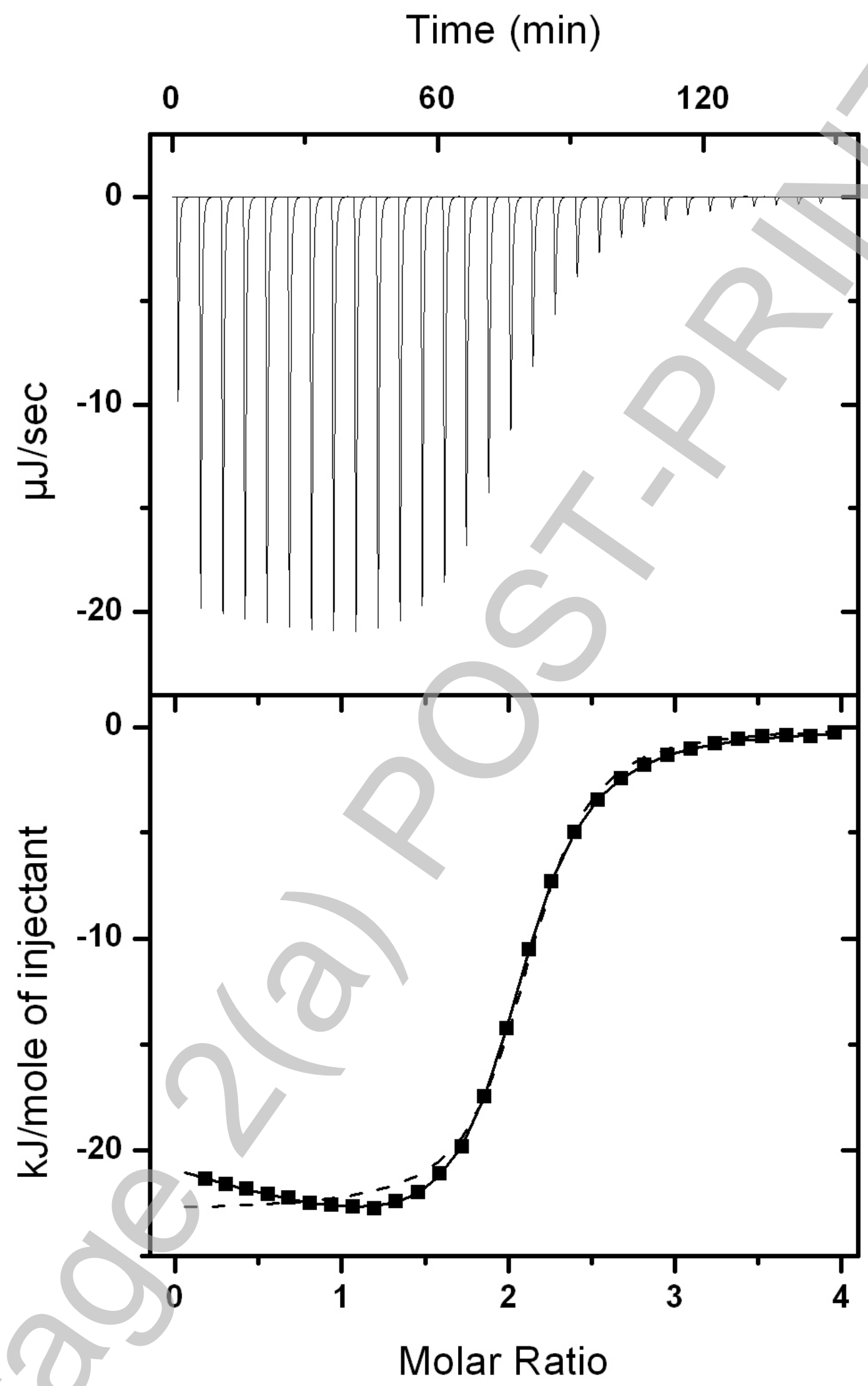

Figure 6

Licenced copy. Copying is not permitted, except with prior permission and as allowed by law. (C) 2008 The Authors Journal compilation (C) 2008 Biochemical Society 
A

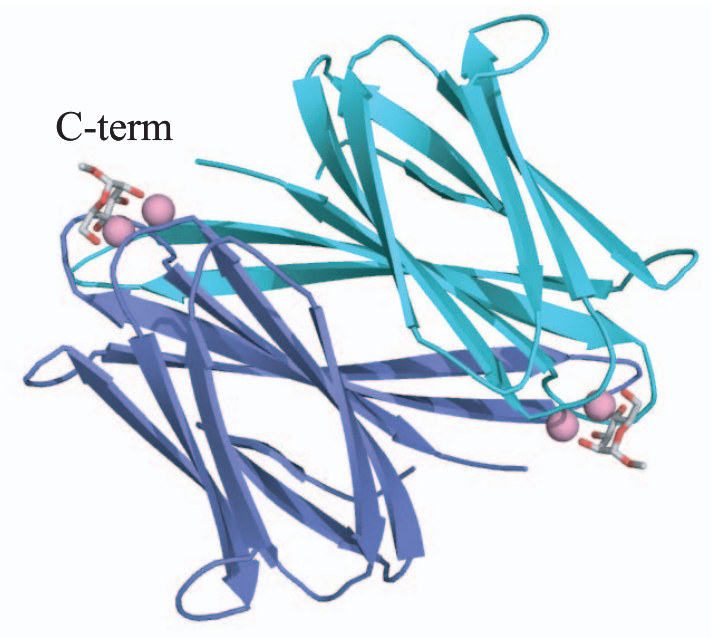

B
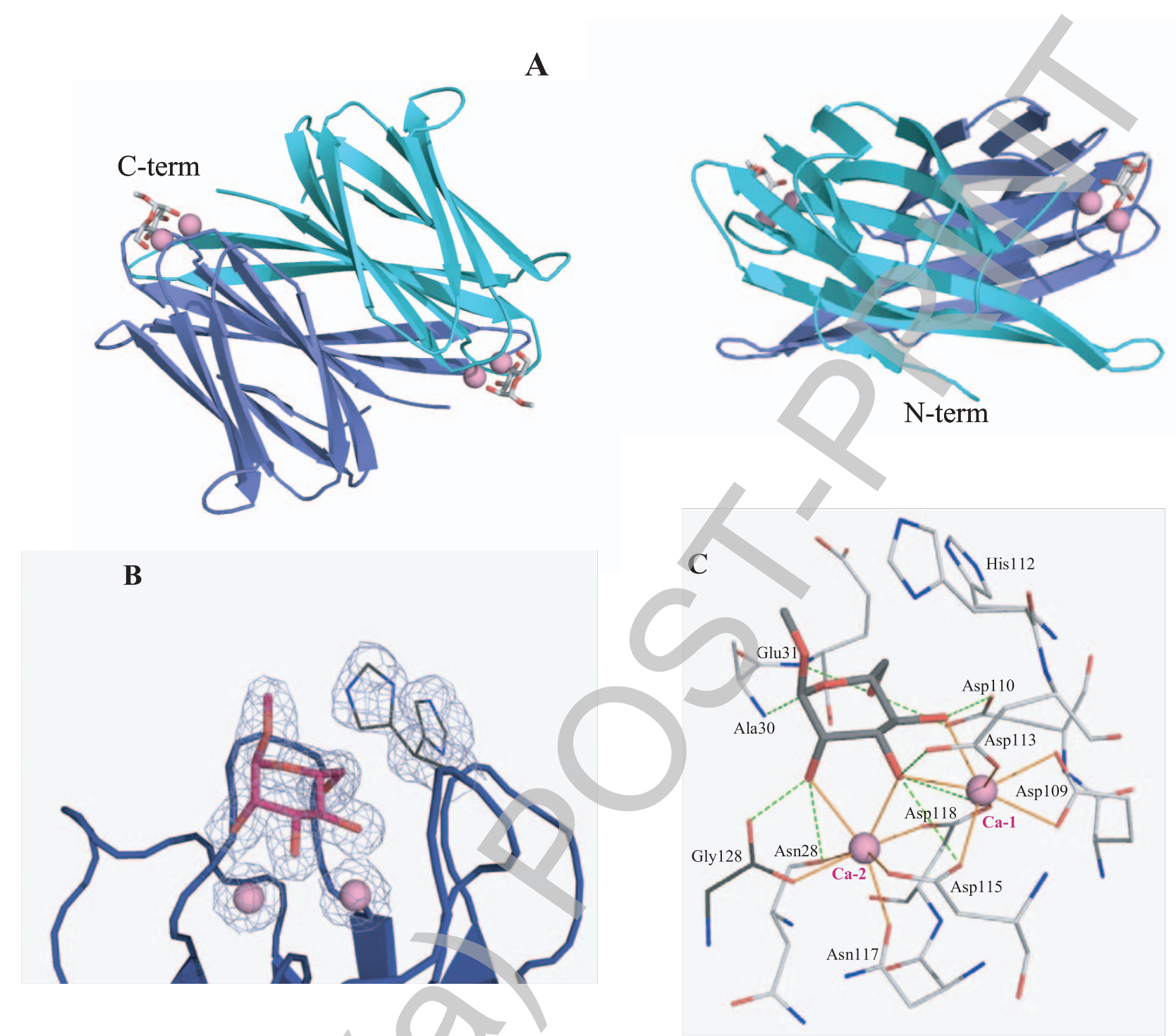

D
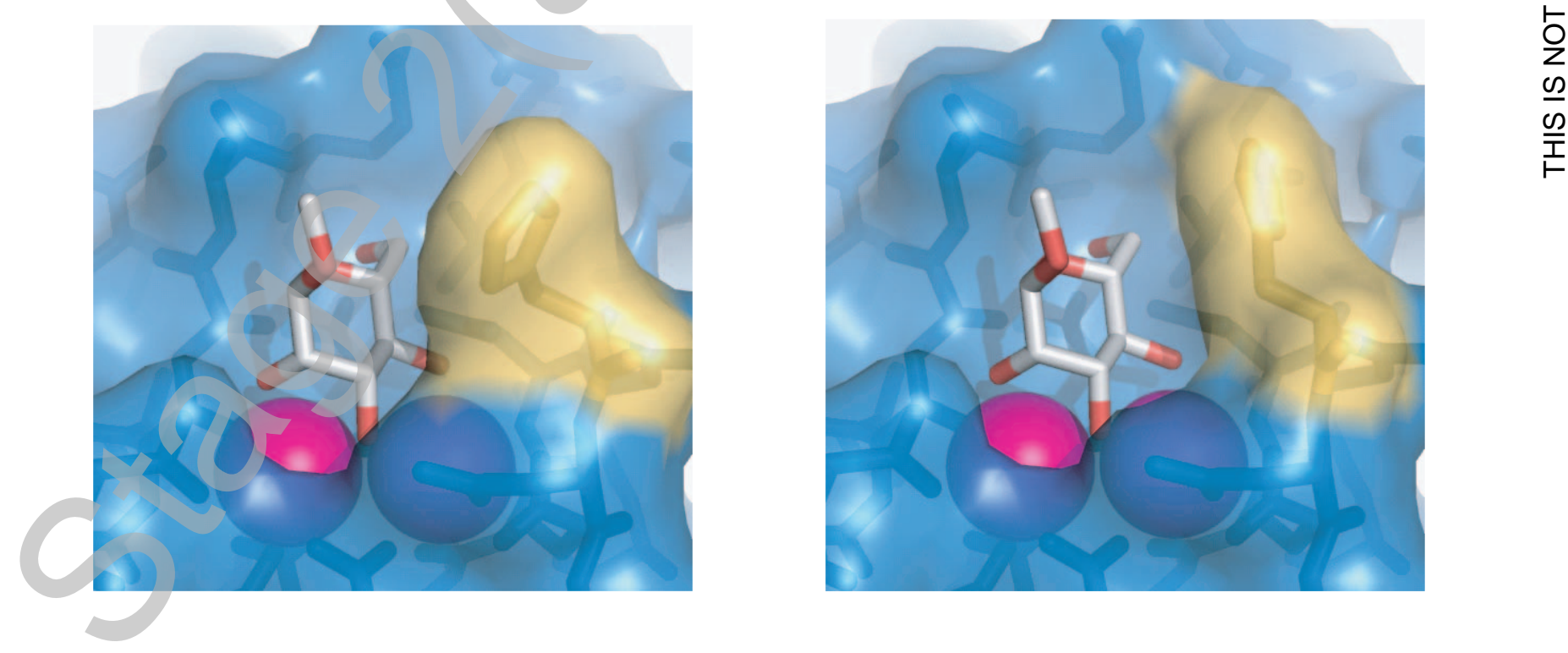


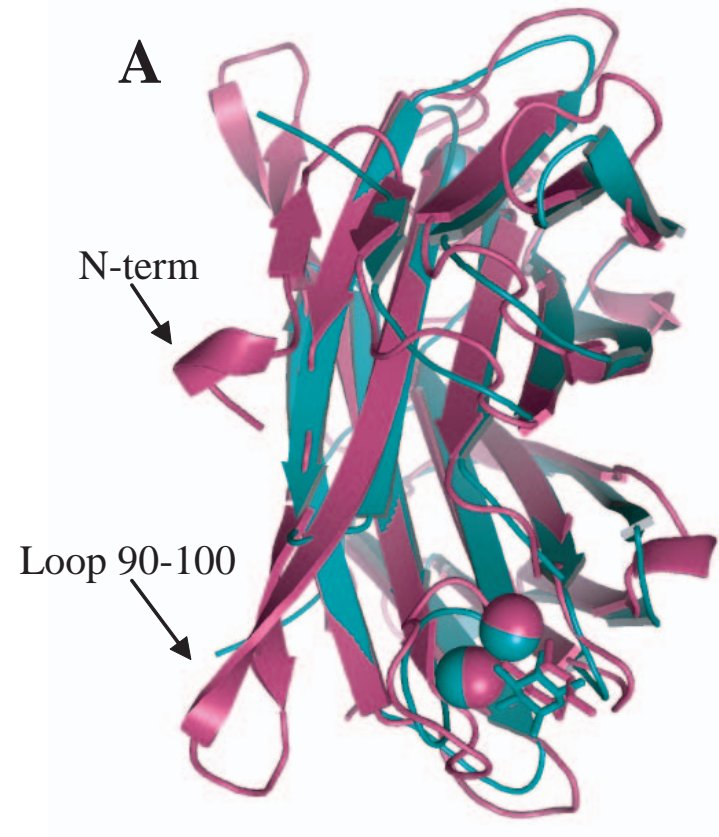

B
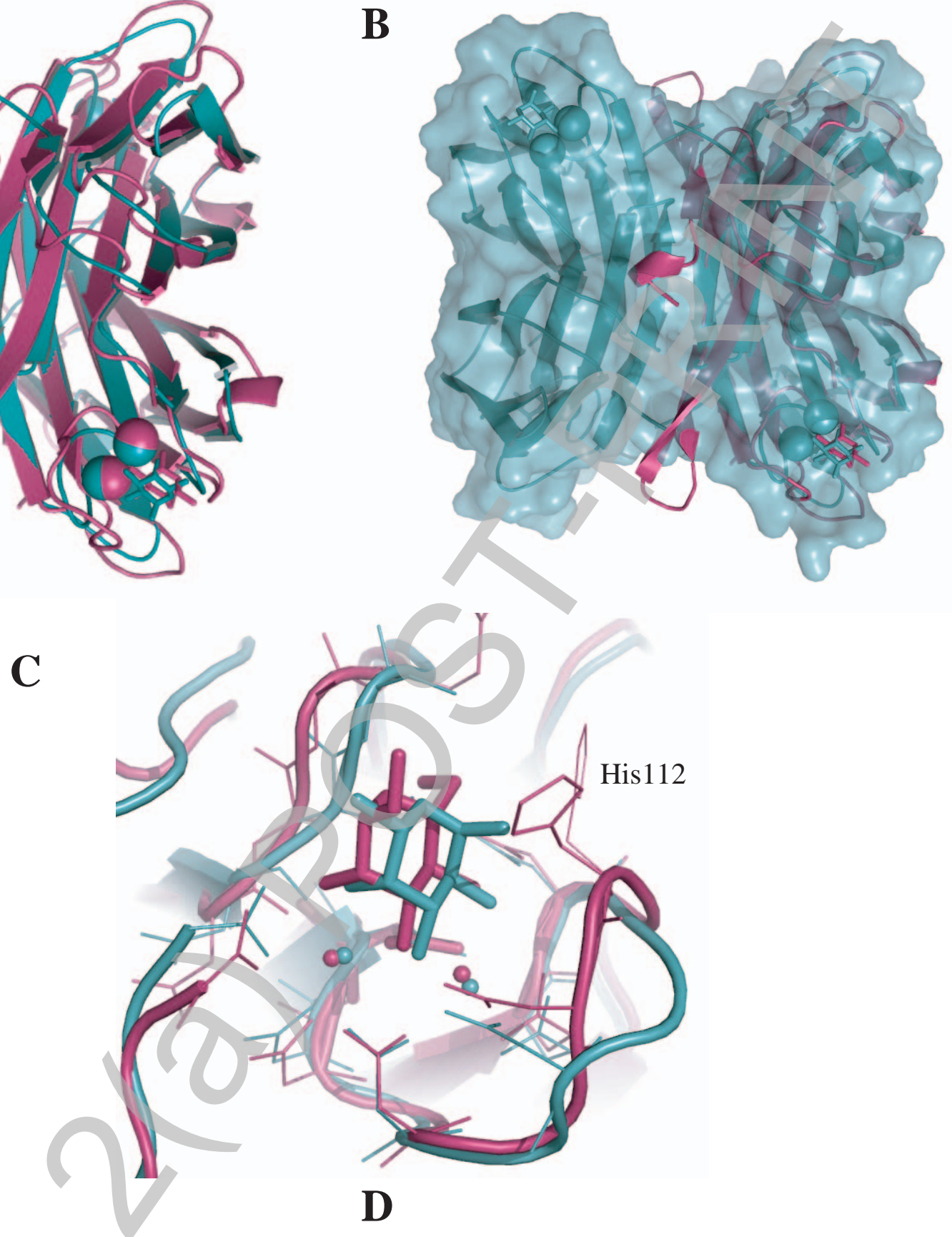

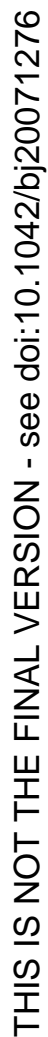
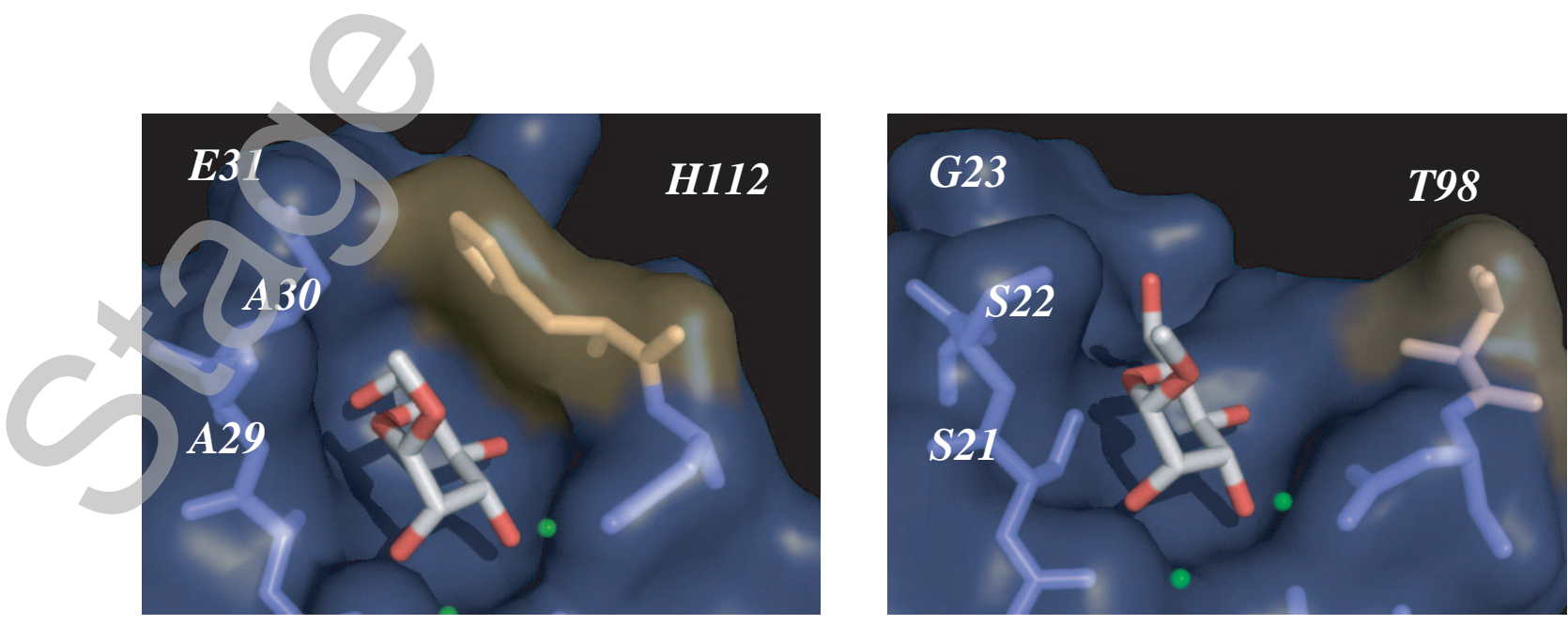

Licenced copy. Copying is not permitted, except with prior permission and as allowed by law. (c) 2008 The Authors Journal compilation (c) 2008 Biochemical Society 